\title{
COMBATE A INCÊNDIO NO ESTADO DE PERNAMBUCO: DO PIONEIRISMO AO “EMBRIÃO” INSTITUCIONAL
}

FIRE FIGHTING IN PERNAMBUCO STATE: THE PIONEERING THE LATEST MODEL.

COMBATE EL FUEGO EN PERNAMBUCO: DEL PIONERO AST EL MODELO ACTUAL.

\section{LUTTE CONTRE L'INCENDIE DANS L'ÉTAT DU PERNAMBUCO: DU PREMIER SERVICE AU GROUPE QUI DÉTIENT LA MISSION AUJOURD-HUI}

\section{RESUMO}

\author{
Cristiano Correa ${ }^{1}$ \\ Ivo Vasconcelos Pedrosa ${ }^{2}$ \\ Getúlio Sena ${ }^{3}$ \\ José Jéferson Rêgo e Silva ${ }^{4}$
}

Este artigo apresenta pesquisa que põe em pauta a criação do primeiro serviço de combate a incêndios no Estado de Pernambuco. Fundado durante o período de dominação holandesa, sendo em princípio, o primeiro serviço organizado de combate a incêndio do Brasil, evidenciado pelos documentos e registros históricos citados. Discorredo-se em seguida, quanto ao renascimento da tarefa de conter as chamas de forma sistemática, após a expulsão holandesa, ainda durante o Brasil Colônia Portuguêsa. Chega-se a criação da Companhia de Bombeiros do Recife, embrião do Corpo de Bombeiros Militar de Pernambuco, órgão responsável pela tarefa em dias contemporâneos.

Palavras - chave: Combate a Incêndio, Pernambuco, História do Corpo de Bombeiros, Província de Pernambuco.

\section{ABSTRACT}

This article presents a research that put on question the criation of first fire's combat service organized of the Pernambuco State. Funded during Dutch domination period, it being in principle, the first fire's combat service organized from Brazil, it showed by documents and cited historical records. By addressing, then as the task renaissance to contain the flames sistematically, after Dutch expulsion, even during Portuguese colony Brazil. Arrieving to the creation of the firefighters company of Recife, embryo of the firefighter department of Pernambuco, agency responsible for the task nowadays.

Keyword; Pernambuco; History of Fire Department; Pernambuco Province.

\section{RESUMEN}

Este artículo presenta una investigación que el debate de lacreacióndel primer servicio de extinción de incendiosenel estado de Pernambuco.Fundada durante el período de dominación holandesa, y, en principio, elservicio de extinción de incendiosprimero organizado en Brasil, acreditado por documentos históricos y registros citados. Comenta y luego como elrenacimiento de latarea de contenerlasllamas de manera sistemática, después de laexpulsión holandesa, incluso durante elportugués de Brasil colonial. Conseguir lacreación de Cuerpo de Bomberos Del Recife, embrióndelCuerpo de Bomberos de Pernambuco, elórgano encargado de latareaendíacontemporáneos.

Extinción de incêndios; Pernambuco; Historia del Departamento de Bomberos; Provincia Pernambuco.

\footnotetext{
${ }^{1}$ Doutorando do Programa de Pós-Graduação em Engenharia Civil -UFPE;

${ }^{2}$ Docente Permanente do Mestrado em Gestão do Desenvolvimento Local Sustentável - FCAP/UPE;

${ }^{3}$ Mestrando do Programa em Gestão em Educação, Cultura e Identidade - UFRPE/FUNDAJ; Historiador - UFPE.

${ }^{4}$ Doutorado em Engenharia Civil - Wessex Institute of tecnology Portsmonth University(1993). Atualmente é professor associado IV do Departamento de Engenharia Civil da Universidade Federal de Pernambuco.
} 


\section{COMBATE A INCÊNDIOS}

Prometeu sobe ao céu com um galho de uma planta - o funcho -, rouba uma semente do fogo de Zeus e a traz para a terra ardendo no funcho. Prometeu distribui o fogo entre os homens, (...).O fogo roubado por Prometeu, que vem de uma semente de fogo, é um fogo que morre, deve ser vigiado para ser preservado. Tem um apetite semelhante ao dos mortais, faminto.(MINDLIN,2002:152).

A importância do domínio do fogo como uma das mais espetaculares inovações tecnológicas vividas pela humanidade fica evidenciada no trecho acima, que de maneira metafórica expressa o tamanho da conquista e do risco que este domínio representa.

O fogo em essência é a reação química de combustão, ou ainda, de oxidação autosustentável onde são liberados luz, calor, fumaça e gases (SÃO PAULO, 2006). Portanto, com esta luz e principalmente calor, os primeiros seres humanos aqueceram-se, cozeram seus alimentos, afugentaram seus predadores, forjaram metais e realizaram mais uma gama de inovações que os ajudaram a aperfeiçoar suas relações com a Terra.

Portanto, em essência, o fogo em suas várias formas, tornou-se um instrumento poderoso à nossa espécie. Tão grande, porém, quanto este domínio tecnológico, são as preocupações com este fenômeno quando fora do controle humano. Incêndio é definido como o fogo que foge ao controle, progredindo de forma violenta e causando destruição(CORRÊA, 2006: 36).

Sumariamente pode-se afirmar que o domínio do fogo foi uma das maiores conquistas da história da humanidade, contudo a perda deste domínio (incêndio) gera "um expoente no embate entre o homem e a natureza e vem causando prejuízos e temores às sociedades ao longo da história" (SILVA e JESUS, 2010: 2).Por sua vezRybczynski(1996: 104) argumenta que: "o incêndio pode ser considerado como um dos grandes males da civilização; (...) o homem tem enfrentado, ao longo da história, grandes e famosas catástrofes ligadas a incêndios."

Visto o comentado acima, difícil é precisar a origem da arte de conter incêndios ou, como costumeiramente emprega-se, o Combate a Incêndios (CI).Lobo (2002) expressa a possibilidade de análise da historiografia do Corpo de Bombeiros a partir de duas vertentes: a vertente europeia que busca descrever a história das atividades de bombeiros e de defesa civil; na vertente americana, não obstante também se preocupar com a história, versa sobre o desenvolvimento tecnológico e a constituição de indústrias de equipamentos para bombeiros.

Remotamente ainda no Código de Hamurabi, imperador babilônico do século XVII a.C, são previstas um conjunto de regras de prevenção a incêndios (IBGE, 2010, apud CORRÊA, 2011: 38).

Segundo a mesma fonte, na China no ano 564 a.C., já existiam relatos de um grupamento de pessoas encarregadas de combater incêndios.Na Grécia, trezentos anos do início da era cristã, a atividade era exercida por grupos de escravos treinados.O primeiro registro oficial, porém, de uma brigada de contenção de incêndios é em 27 a.C. quando o Imperador Romano Augusto a institui, formada por soldados e escravos(NATIVIDADE, 2009: 412). 
Na Idade Média, tinha-se no incêndio um conceito relativo, pois se considerava que tal sinistro era algo inevitável e muitas vezes uma providência divina. Chegado o século XVI, espalha-se na Europa a produção dos artesãos. Nesse momento os incêndios tornam-se mais frequentes. Na metade do século XVII, se tinha como materiais básicos de CI, machados, enchadões, baldes e outras ferramentas.

Van Der Heyden, em 1699, inventa a "bomba de incêndio", possibilitando um salto qualitativo na luta contra as chamas. Anos após o mesmo inventor ganha notoriedade, ao desenvolver mangueiras de incêndio de couro com conexões em bronze que, acopladas à bomba, puseram fim ao uso do balde com o lançamento de jatos de água em várias direções.

Com relação ao $1^{\circ}$ Corpo de CI moderno, fontes apontam em direções difusas. Alguns afirmam que o primeiro Corpo de Bombeiros Profissional foi criado em Berlim, Alemanha, em 1851 (IBGE, 2010, apud, CORRÊA, 2011:39). Afirma-se também, que no fim do século XVIII, em Paris (França), surge uma companhia de sessenta "guarda bombas", uniformizados e pagos, sujeitos a disciplina militar e que deste marco histórico avante, os serviços se multiplicaram pelas grandes cidades da época, sejam administrados pelo Estado, sejam por iniciativa de companhias de seguro.

Existe inclusive a hipótese que o primeiro Corpo de Bombeiros moderno tenha surgido em terras lusitanas em 1728, com o nome de Companhia de Fogo do Porto, criado por decreto de Dom João $5^{\circ}$ (PEREIRA e PITA, 2007:62).

Diante do apresentado nos parágrafos anteriores, o presente artigo tem por objetivo realizar um levantamento histórico acerca do serviço de combate a incêndios em terras pernambucanas.

Uma vez que, não obstante o Corpo de Bombeiros Militar de Pernambuco adotar em seu Brasão a data de fundação de 1636, a Corporação realiza a contagem de seu aniversário de fundação a partir do ano de 1887. Então, através do levantamento dos dados históricos, ficam evidenciadas as razões que justificam os dois marcos históricos.

\section{PRIMEIRO SERVIÇO DE COMBATE A INCÊNDIO EM PERNAMBUCO}

Desde o advento das capitanias hereditárias, que o nome Pernambuco ecoava como um pólo de desenvolvimento na então colônia portuguesa do Brasil. Baseado na agricultura e no comércio, o território que hoje conhecemos por Estado de Pernambuco passou a ser cobiçado por nações européias. Ajuntando-se a isto a posição geográfica, a região Nordeste do Brasil, e em especial este Estado, à época chamado província, sofreram intensas dominações holandesas, no século XVII (DIAS, 2005:02).

É neste contexto que, após inúmeras derrotas no interior nordestino, no fim do mês de novembro de 1631, Olinda, que era, juntamente com Igarassu, pólo de desenvolvimento da colônia Portuguesa, e nesta data sofrendo invasão de holandeses, é incendiada quase que por completo, inaugurando a história de grandes sinistros em territórios pernambucanos, segundo Mello(2001:52). 
Tal fato tem por origem a chegada da esquadra de D. Antonio de Oquendo (Representante da Coroa Portuguesa), gerando enorme precipitação, por parte dos holandeses, que, superestimando o poder bélico da dita esquadra, abandonaram Olinda e atearam fogo na cidade, enquanto recolhiam-se para Recife, por julgar mais estratégico. Provavelmente este foi o primeiro grande incêndio em terras pernambucanas. Tal fato histórico foi evidenciado pelo autor português da época, Fernandes Gama, que assim narrou o fato:

\begin{abstract}
mandou vanWaerdemburg pôr fogo a Olinda, ordenando à guarnição que ateado o incendio, se retirasse, para que os nossos no mesmo momento do delicto, não dessem o castigo; porém apezar da celeridade com que se retiraram, não se livraram, que de uma emboscada os assaltassem nossas armas, 'tanto mais temíveis quanto a occasião lh'as representava duplicadamente colericas. Muita gente lhes matou, e ferio, e muita mais pereceria, si a maior parte dos nossos não acodira a apagar o fogo, que ateando-se nos combustives, de que os Hollandezes tinham enchido as casas, tornou infructiferas todas as deligencias. Ardeo em breve espaço no dia 25 de Novembro de 1631 toda a Villa d'Olinda, tão celebrada pelo cormmercio, como ennobrecida pelos edificios, salvando-se neste geral incendio uma caza terra, que a sorte reservou para memoria da perda. Sabendo depois quanto era fraco o reforço que Albuquerque recebêra, os GeneraesHollandezes, se arrependeram, mas mui tarde. (GAMA, 1921: 232).(grafia do texto original).
\end{abstract}

Assim o Governo Batavo fortalece suas posições em Recife tendo como principal mola propulsora de desenvolvimento o Porto da cidade, que rapidamente ganha um complexo de armazéns e edifícios comerciais, além de servir como sede das residências oficiais dos líderes invasores. Os métodos logísticos precários, com os quais as mercadorias mais diversas eram armazenadas com muito pouco ou nenhum critério de segurança, acrescendo-se as intenções criminosas que visavam os prêmios de seguro, sendo, à época, hábito entre os holandeses a aquisição de apólices, criam a atmosfera para ocorrências de incêndios e consequentemente salvamentos.

Desta feita é criado o primeiro serviço de Combate a Incêndios das Américas, como se pode observar no texto do livro "Tempo dos Flamengos", do Professor José Antonio Gonsalves de Mello, quando faz tradução do documento original DagelijkscheNotule,ou simplesmente Dag Notulen, de 07 de agosto de 1636:

Outro serviço público importante foi o que criou o serviço de extinção de incêndios no Recife. Vê-se, também, que nesta ocasião o Recife já deveria contar com o número relativamente grande de construções, pois a cidade foi dividida, para referido fim, em dois distritos: o do Norte e o do Sul. Encarregados deles (na qualidade de brantmeesters) foram inicialmente Johan Schaep, do primeiro e do segundo CristoffelEyerschettel, aos quais foi incumbido: devem exercer a fiscalização segundo as instruções e fazer uma relação do que cada casa deve dar para a manutenção das vigias (MELLO, 2001: 60).

Como é visto a partir do fragmento acima os acontecimentos de incêndios e vidas em risco eram frequentes, sendo neste mesmo ano, 1788, especificamente em 21 de fevereiro, promulgado um regimento para os serviços dos navios ancorados no Porto do Recife, com o fim de socorrerem-se mutuamente por ocasiões de incêndios e salvamentos a bordo, entre outros sinistros (CAVALCANTI, 2005:30).

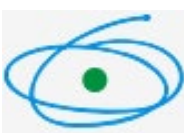


Quanto à abrangência, importância e legitimidade das Dag. Notulen, Miranda (2011),em sua tese de PhD pela Universidade de Leiden-Holanda, esclarece:

As DagelijkseNotulen constituem um registro diário dos atos do governo da WIC '(West-IndischeCompagnie - Companhia Holandesa das Índias Ocidentais)' no Brasil, formado pelo Conselho Político (1630-1637), Alto e Secreto Conselho (1637-1644) e Alto Governo (1644-1654).(MIRANDA, 2011: 20)

Sendo assim, alguns historiadores e pesquisadores (MELLO, 2001; CAVALCANTI, 2007; CORREAA, 2011)apontam o pioneirismo do Serviço de Extinção de Incêndio na América ao Estado de Pernambuco, pois o serviço público instituído através da Dag Notulen em destaque é instituído duzentos e vinte anos antes da fundação do "Corpo de Bombeiros Provisórios da Corte" (NATIVIDADE, 2009, p.412), realizada por Dom Pedro II em1856. Sendo assim, constitui-se como um momento histórico para o Estado de Pernambuco, por representar os primórdios do serviço que hoje é desenvolvido pelo Corpo de Bombeiros Militar de Pernambuco.

Portanto em Pernambuco o primeiro grande, e criminoso, incêndio bem como o primeiro serviço organizado de combate a incêndios, contraditoriamente foram gerados por mãos holandesas.

3 Serviço de Combate a Incêndio na Província Portuguesa de Pernambuco

Quando da expulsão dos Holandeses, invasores que administraram a Província de Pernambuco por mais de duas décadas e implantaram o serviço de extinção de incêndios, houve a interrupção da execução do mesmo, ficando o combate aos incêndios sendo realizado, de forma improvisada, por pessoas não profissionais(CORRÊA, 2011:24).

Após a retomada de todas as posições, das mãos holandesas, Pernambuco volta a fazer parte do Brasil Colônia Portuguesa. As obras em infra-estrutura deixadas pelos holandeses catalisam o potencial do Porto do Recife, permanecendo este como um dos principais da Colônia, em pleno século XVIII, porém a situação de armazenagem, transporte e comercialização, dos inúmeros produtos lá passantes, em muito se distancia de uma prática segura, ficando evidente a preocupação com o atendimento de sinistros nos idos de 1788. Em 18 de fevereiro de 1788, o então Governador da província Dom Tomas José de Melo oficia ao Ministro de Ultramar, em Lisboa, pedindo a remessa de uma bomba para a extinção de incêndios. Meses depois, em 03 de novembro do mesmo ano, em novo ofício informa a chegada da dita bomba, conforme se vê:

Logo que se deu fundo a charrua de S. Majestade em que V. Exa. fez vir a bomba para apagar fogo, dei toda pressa para que desembarcasse e não seguiu sem fazer conduzir adiante de mim para o Colégio em que resido, mas não eram passadas dez horas quando se ateou um grande incêndio em um armazém cheio de alcatrão, palhas de coqueiro, caibros e madeiras (...) cercadas de casa (...); porém fazendo eu conduzir a bomba e água necessária para laborar, conseguiu-se, felizmente, que só ardesse a propriedade em que estava situado o armazém ficando ilesas as que lhe ficavam em redor (PEREIRA DA COSTA, apud, CAVALCANTI, 2007: 29). 
As estruturas portuárias padeciam com o binômio falta de estrutura logística e intenções criminosas, atingindo patrimônio e vidas humanas. Em 1855 já existe uma sofisticada organização de anúncio e combate dos sinistros. A forma de alarme desenvolvida nessa época era bem peculiar; os sinos da igreja mais próxima soavam informando o acontecimento de focos de fogo ou perigo a vidas, sendo repetidos os toques pelas igrejas no entorno, estas faziam soar o alarme a outras mais afastadas que repetiam o toque, até que todos os envolvidos fossem alertados. Esse hábito perdurou até o final do século XIX. Isto fica evidenciado nos trechos extraídos das páginas 127 a 130 e 328 a 330 da Revista do Instituto Arqueológico, Histórico e Geográfico Pernambucano (IAHGP), em seu volume 27:

(...) era hábito as igrejas do Recife dar sinal de alarme, toda vez que se manifestava incêndios em determinado ponto da cidade ou subúrbio,(...) Logo que se manifestar o incêndio em qualquer parte da cidade, a igreja que mais próxima lhe ficar dará imediatamente o sinal por meio do sino maior que tiver, e o repetirá enquanto durar o incêndio. $\mathrm{O}$ sinal de 5 badaladas se o incêndio for na freguesia do Recife, de 6 se for na de Santo Antonio, de 7 se for na de São José. (IAHGP, 1925:328).

Em que pese a engenhosidade da comunicação, nestes eventos não existia um grupo organizado e treinado, mas sim uma tentativa de ajuntar esforços para combater as chamas e salvar vidas. Veja-se outro trecho de documentos extraído das páginas em epígrafe do volume 27 do IAHGP:

O sacristão ou guarda da igreja que primeiro anunciar o incêndio tomará nota do nome, moradia, qualidade e sinais característicos da pessoa que lhe der o aviso (...) As demais igrejas da cidade, (...), repetirão o sinal com o mesmo número de badaladas que tiver dado àquela que primeiro anunciar o incêndio, (...) Em cada freguesia da cidade, serão, pela Polícia, organizados em capatazias os pretos (...), correrá ao lugar o Diretor de Obras Públicas, com seus engenheiros e trabalhadores e tomará a direção do trabalho (...) Ao sinal de incêndio, o Inspetor do Arsenal da Marinha mandará, com a possível prontidão, o seu ajudante com a bomba e trabalhadores respectivos. O Diretor do Arsenal de Guerra também enviará artífice e a bomba; apresentar-se-á sem demora, no lugar do incêndio, o capataz da alfândega com bomba e trabalhadores da capatazia (...) devendo (...) levarem consigo escadas e baldes (...) Na repartição das Obras Públicas, haverá uma bomba pronta para ser empregada, acudindo a qualquer incêndio (...) Os Subdelegados das freguesias permanecerão vigilantes com os seus agentes (...) A Polícia ocupar-se-á em tomar medidas de segurança (...) Os Corpos da Guarda Nacional, ao sinal de Incêndio, formarão nos lugares de suas paradas (...), a Força de Primeira Linha se conservará pronta em seus quartéis (...); das praças da Companhia de Cavalaria serão, imediatamente, destacadas uma ordenança a disposição do Diretor de Obras Públicas (...) Logo que houver anuncio de fogo, todos os chafarizes da freguesia em que ele se der estarão abertos e os seus encarregados prontos (IAHGP, 1925:329).

Acima, veem-se trechos da normatização, assinada em 8 de janeiro de 1855 por José Bento da Cunha Figueiredo, Presidente da Província, que normatizava o atendimento a incêndios.

É óbvio que por melhor que fosse a intenção de todos os envolvidos, um sistema rudimentar e complicado como este não era eficiente para prevenir ou sequer conter os incêndios. Veja-se um trecho do Jornal do Recife de1885: 


\begin{abstract}
Abertas as portas pelos operários do Arsenal de Guerra, verifiquei logo, pela intensidade do fogo que lavrava em todo pavimento térreo e acometia o andar superior, que era impossível salvar o prédio ao qual ele se prendia e tentei todos os esforços para circunscrevê-lo e diminuir-lhes os estragos. Não dispondo a providência de meios apropriados nem de pessoal habilitado para o serviço de extinção de incêndio (grifo do autor desteartigo)(JORNAL DO RECIFE, apud, CAVALCANTI, 2007: 33).
\end{abstract}

Nessas tragédias constantes, destaca-se o incêndio do teatro Santa Isabel. É importante compreender que em 1869, ano do evento, Recife continuava a ser uma cidade com ligações profundas com seu Porto. Os principais empreendimentos comerciais e boa parte de sua população estava concentrada nos Bairros da Boa Vista, Santo Antonio e São José, na verdade ilhas ou extensões de terra circunvizinhasà zona portuária, e como grande centro cultural desta cidade em desenvolvimento, estava o dito teatro, que, além de abrigar as manifestações culturais daquela data, era o ponto de encontro e debate dos intelectuais e poderosos. Mais do que um prédio que ardia em chamas, um símbolo augusto daquelas pessoas decaia em brasa. $\mathrm{O}$ autor recifense Mário Sette em sua obra "Maxambombas e maracatus", narra:

Tarde de 20 de setembro de 1869. Os sinos da igreja de São Francisco tocam a rebate. Outras igrejas imitam. A fumaça e as chamas bem altas indicam o Bairro de Santo Antônio (...) E a noticia corre tremenda, desoladora: o Teatro Santa Isabel está pegando fogo (...), vem a bomba do Arsenal da Marinha com os imperiais marinheiros, acodem os trabalhadores da capatazia da Alfândega. Escravos trazem baldes com água de um chafariz perto. Galopam praças da cavalaria (...) As labaredas lambem cenários, bombinelas, ribalta, velórios, espelhos, madeira, bastidores, cortinas, móveis (...) só ficam as paredes externas. Fora-se o Teatro Santa Isabel.(SETTE, 1981:93).

É nessa comoção após a perda do teatro e tudo o que ele representava, que é posta em cheque a eficiência do arranjo de esforços implementado em 1855, para combater e prevenir incêndios, e quase um ano após acalorada reação popular, o então Vice-Presidente da Província de Pernambuco, desembargador Francisco de Assis Pereira Rocha, sanciona a Lei no 958 de 12 de julho de 1870, criando a Companhia de Sapadores Bombeiros (termo ainda hoje utilizado em Portugal) na cidade do Recife. No documento é retratada uma companhia com oitenta praças comandada por um Capitão (Engenheiro indicado pela Presidência da Província) com a responsabilidade de extinguir incêndios e realizar salvamentos de pessoas e bens, sendo subdividida em quatro frações de 20 homens onde um era o Sargento nomeado pelo comandante. Essa fração era responsável por um bairro do Recife. A legislação falava ainda do material: bombas, tonéis ou pipas montadas sobre rodas (veículos), escadas, machados, e todos os instrumentos cedidos ao serviço [CAVALCANTI, 2007, p.44-46]. Destaca-se que esta lei não saiu do papel, por falta dos recursos necessários à implantação e ativação do serviço de extinção de incêndios na cidade do Recife.(PEREIRA, apud, CORRÊA, 2011: 28).

\footnotetext{
${ }^{1}$ Sapadores Bombeiros, termo que designa os profissionais que trabalham no combate a chamas utilizando instrumentos hidráulicos (Bombeiros) e material de sapa como: pás, machados, enchadas etc
} 
De fato a Companhia de Bombeiros do Recife, apenas passa a existir quando é promulgada a Lei $\mathrm{n}^{\circ}$ 1.860, de 11 de agosto de 1885, cujo texto, já previa convênio de parceria entre o Governo da Província e as empresas de seguros existentes na época, com manutençãodo serviço regida através da Lei $n^{\circ} 1.654$, de 1882, sendo este, talvez, oficialmente, um dos primeiros exemplos de Parceria Público-Privada (PPP) do Estado de Pernambuco.

Mesmo assim, após a promulgação da legislação acima mencionada, somente dois anos depois, a 23 de setembro de 1887, o Governo Provincial nomeava o Capitão Joaquim José de Aguiar, Comandante da Companhia de Bombeiros do Recife, sendo ativada em 20 de outubro de 1887, segundo a primeira Ordem do Dia daquele Oficial Comandante (CORRÊA, 2011:28). Essa data ainda é um marco histórico, sendo computada a idade corporativa do Corpo de Bombeiros Militar de Pernambuco a partir deste fato, uma vez que representa o momento em que a Corporação, através dos serviços prestados à população, passa a ter um caráter perene enquanto instituição que perdura até os dias atuais.

A estatística oficial aponta que no primeiro ano de completa ativação (janeiro a dezembro de 1888) foram registrados 24 incêndios sendo 11 classificados como médios ou grandes (CAVALCANTI, 2007: 57).

Todo o exposto acima corrobora com Lobo (2002: 20), quando afirma que "com o crescimento das cidades e o aumento populacional, torna-se cada vez mais necessário um serviço técnico e especializado para o combate a incêndios e outros tipos de situações de emergência”. Dessa forma, percebe-se que o clamor popular pressiona o Estado a implantar o Corpo de Bombeiros em Pernambuco. Em que pese o mesmo autor afirmar que "os modelos modernos de serviços de bombeiros, em sua maioria, são organizados localmente. Nas grandes cidades, com um serviço público profissional sob a jurisdição do município”. (LOBO, 2002: 20). Diferentemente do que têm-se em todo o Brasil, onde os Corpos de Bombeiros profissionais são organizados sob a égide dos Estados federados.

Em que pese o embrião institucional do Corpo de Bombeiros do Estado de Pernambuco ser inegavelmente a Companhia instituída pela Lei $\mathrm{n}^{\circ} 1.860$, de 11 de agosto de 1885, a importância do serviço estabelecido no Brasil holandês, especificamente na cidade de Recife, é reconhecidana identidade corporativa, uma vez que, no século XXI, a instituição adotou o ano 1636, da época dos Brantmeesters - Mestres de fogo holandeses, na heráldica de seu brasão.

Figura 1 - Brasão do Corpo de Bombeiros Militar de Pernambuco

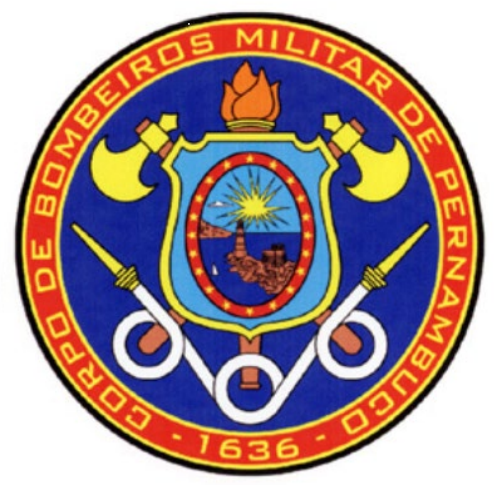




\section{CONCLUSÕES}

Este artigo apresenta, por meio da análise de levantamentos históricos, o primeiro serviço de combate a incêndio no território do Estado Federado Brasileiro de Pernambuco. Serviço instituído pelo governo holandês, ora invasor, que confrontado com a necessidade de manter a incolumidade pública, principalmente no entorno das ilhas do Recife, promulga Dag. Notulen criando a função de Brantmeesters, que tinha como principal atribuição prevenir e combater sinistros, sobretudo incêndios, na cidade.

Também é examinada a organização deste serviço após a expulsão batava, inicialmente com arranjos envolvendo vários "atores" não profissionais de combate às chamas. O artigo alcançou a fundação da Companhia de Bombeiros do Recife, ente que, transformadaao longo das décadas, deu origem ao Corpo de Bombeiros Militar de Pernambuco, instituição responsável pelo serviço de prevenção e combate a incêndios nos dias atuais. 


\section{REFERÊNCIAS}

CAVAlCANTI, Carlos B. Guerreiros da Paz. Recife, PE: Editora Própria, 2007.

CORREAA, Cristiano. A contribuição dos serviços de Combate a Incêndios (CI) e Salvamento (S) para o Desenvolvimento Sustentável (DS): Um panorama pernambucano. Dissertação, Recife, 2011.

DIAS, Érika Simone de Almeida Carlos. A Capitania de Pernambuco e a instalação da Companhia Geral de Comércio, publicado nas Actas do Congresso Internacional Espaço Atlântico de Antigo Regime: poderes e Sociedade. Lisboa, Portugal 2005.

GAMA, Joze B. F. Memórias históricas da Província de Pernambuco, 1921. Disponível em: http://www2.senado.leg.br/bdsf/ handle/id/221727 Acesso em: 22dez14.

IAHGP, Instituto Arqueológico, Histórico e Geografico de Pernambuco. Revista do Instituto Arqueológico, Histórico e Geographico de Pernambucov.27, Recife: IAHGP,1925.

JORNAL DO RECIFE. Edição de 12 de Abril de 1885, apud, CAVALCANTI, Carlos B. Guerreiros da Paz. Recife, PE: Editora Própria,

LOBO, Carlos Eduardo Riberi. O Corpo de Bombeiros em São Paulo/1970-1995. Modernização, Políticas Públicas e Cidadania. Dissertação, São Paulo, 2002. Disponível em: http://www.sapientia.pucsp.br/tde_arquivos/17/TDE-2007-08-07T08:05:49Z-4024/ Publico/Carlos\%20Eduardo\%20Riberi\%20Lobo.pdf Acesso em: 29dez14.

MELLO, José Antônio Gonsalves de. Tempo dos Flamengos. Recife: Topbooks, 2001.

MINDLIN, Betty. O Fogo e as Chamas dos Mitos. Estudos Avançados. São Paulo - SP, v.16, n.44, p.149-169, 2002.

MIRANDA, Bruno Romero Ferreira. Gente de Guerra: Origem cotidiano e resistência dos soldados da Companhia das Índias Ocidentais no Brasil (1630 - 1654). Tese de PhD pela Universiteit Leiden, Holanda, 2011.

NATIVIDADE, Michelle Regina de. Vidas em Risco: a identidade profissional dos Bombeiros Militares. Psicologia e Sociedade, v.31, n.3, p.411-420, 2009.

PEREIRA, Ana Leonor ; PITA, João Rui. Miguel Bombarda (1851-1910) singularidades de uma época, Coimbra: Editora da Universidade de Coimbra, Portugal, 2006.

PEREIRA DA COSTA, F. A. Anais Pernambucanos v. VI, apud, CAVALCANTI, Carlos B. Guerreiros da Paz. Recife, PE: Editora Própria, 2007.

RYBCZYNSKI, Witold. A vida nas cidades: expectativas urbanas no Novo Mundo. Rio de Janeiro: Record, 1996.

SÃO PAUlO (Estado). Corpo de Bombeiros da Polícia Militar do Estado de. Coletânea de Manuais Técnicos de Bombeiros. v. 1. São Paulo - SP, 2006.

SILVA, Jaqueline N. de; JESUS, Bruna C. Ornelas Silvestre de. Os incêndios nas páginas dos jornais: relatos de casos e o corpo de bombeiros no Rio de Janeiro oitocentista. XII Encontro Regional da ANPUH-Rio. Rio de Janeiro, RJ: XII Anais do XII Enc. Reg. da ANPUH-Rio, 2010.

SETTE, Mario. Maxambombas e Maracatus. Recife, PE: Fundação de Cultura da Cidade do Recife, 1981. 